\title{
Redefining the piscivore assemblage of shallow estuarine nursery habitats
}

\author{
Ronald Baker $^{1,2, *}$, Marcus Sheaves ${ }^{1}$ \\ ${ }^{1}$ School of Marine Biology and Aquaculture, James Cook University, Townsville, Queensland 4811, Australia \\ ${ }^{2}$ Coastal CRC, Indooroopilly Sciences Centre, 80 Meiers Road, Indooroopilly, Queensland 4068, Australia
}

\begin{abstract}
It is often suggested that there are few piscivorous fishes in shallow estuarine habitats worldwide, and consequently that these habitats are valuable as nurseries for juvenile fishes because they provide refuge from predation. Information on the dietary habits of predatory fishes from tropical estuaries remains limited to broad summaries that lack quantitative detail on the fish components of the diet. Consequently, it remains unclear which predators in shallow tropical estuarine nurseries target new recruits. To define the assemblage of piscivorous fishes relevant to the functioning of shallow water nurseries, we examined the diets of predatory fishes from shallow $(<1.5 \mathrm{~m})$ sandy habitats in the lower reaches of 17 tropical estuaries over 6 yr. In total, 51 taxa from 21 families fed on fish, and the piscivore assemblage included many taxa and size classes that have been previously overlooked. Piscivores ranged in size from 15 to $755 \mathrm{~mm}$ and the majority of taxa were piscivorous to some degree from sizes well below $100 \mathrm{~mm}$. All of the smaller piscivores $(<100 \mathrm{~mm})$ mainly preyed on small new recruits, while only some of the larger piscivores did so. The taxonomic and functional diversity in the piscivore assemblage, and the fish community as a whole, highlights the complexity of the role of predation in the functioning of shallow tropical estuarine nurseries. Despite this complexity, it is apparent that predation has the potential to be a major structuring force on shallow water tropical estuarine fish communities.
\end{abstract}

KEY WORDS: Estuary · Nursery ground $\cdot$ Refuge $\cdot$ Piscivory $\cdot$ Diet · Ontogeny

Resale or republication not permitted without written consent of the publisher

\section{INTRODUCTION}

It is widely considered that estuaries, in general, and shallow estuarine habitats, in particular, are valuable nurseries because they provide abundant food and refuge from predation for small and juvenile fishes (e.g. Blaber \& Blaber 1980, McIvor \& Odum 1988, Ruiz et al. 1993, Laegdsgaard \& Johnson 1995). The refuge theory is based, in part, on reports of low abundances of piscivorous fishes within estuarine habitats (e.g. Shenker \& Dean 1979, Rozas \& Hackney 1983, Boesch \& Turner 1984, Patterson \& Whitfield 2000). Sheaves (2001) reviewed the proposition of few piscivorous fishes in shallow estuarine habitats and concluded that it was illdefined and lacking in evidence. Both ideas of refuge and of few predators must be logically placed in context relative to some alternate habitat(s). While several authors have compared abundances of fishes between potential nursery habitats (e.g. Blaber 1980, Robertson \& Duke 1987), the logistical difficulties of sampling fish from multiple habitats with comparable gears makes comparisons of abundances between habitats difficult (Sheaves 2001). It is, however, important to understand the process of piscivory within estuarine habitats, and its influence on their roles as nurseries (Blaber 1986) because such knowledge will ultimately lead to an understanding of how estuarine nurseries function and exactly what makes them valuable.

The level of predator-induced mortality of juvenile fishes is obviously the ultimate factor that determines the importance of predation within shallow-water estuarine-nursery grounds (Sheaves 2001). As much of the shallow nursery habitat in tidal estuaries is intertidal, juvenile fishes utilising shallow waters cannot be site-attached and must use multiple habitats on a daily basis. As a consequence, directly estimating mortality 
by monitoring changes in abundance is virtually impossible, and alternate approaches are needed to examine the role of piscivory. Detailed examination of diets of predators that prey on small juvenile fish is one useful approach to understanding the role of predation in structuring shallow estuarine nursery fish assemblages.

While there is some detailed work on predator-prey dynamics in extensively studied temperate estuarine systems (e.g. Juanes \& Conover 1995, Buckel \& Conover 1997, Juanes et al. 2001), there is far less information available for tropical estuaries in the IndoWest Pacific region. Predator-prey dynamics are likely to be different in tropical systems because they contain very diverse fish assemblages, with the number of species usually an order of magnitude greater than in temperate estuaries, sometimes exceeding 200 species (Blaber 2000). There is little or no demographic data available for the vast majority of these fishes (Blaber 2000). The only published study on recruitment of juvenile fishes into estuarine nurseries in the tropical Indo-West Pacific (Alligator Creek near Townsville, Australia, $\left.19^{\circ} 21^{\prime} \mathrm{S}, 146^{\circ} 57^{\prime} \mathrm{E}\right)$ recorded year-round recruitment with a broad peak during the summer wet season between November and April (Robertson \& Duke 1990b). Most species showed extended recruitment seasons ( $\geq 5 \mathrm{mo}$ ), with irregular pulses of recruits appearing in the estuary during the 13 mo study. Dietary data on piscivorous fishes from the tropical Indo-West Pacific remains limited to broad summaries of the contribution of various prey types (Salini et al. 1990, 1998, Haywood 1998). There are no quantitative data available on spatial, temporal or predator-sizerelated trends in piscivore diets, nor on the composition and size structure of fish prey within predator diets. As a consequence of this paucity of data, our understanding of predator-prey dynamics and the role of piscivory in the functioning of tropical estuarine nurseries are in their infancy.

Information on the diets of piscivorous fishes within estuaries is mostly limited to large piscivores (>100 mm) (e.g. Blaber 1980, 1986, Salini et al. 1990, Patterson \& Whitfield 1996, 2000). Some speciesspecific studies in North America (eg. Hartman \& Brandt 1995, Buckel \& Conover 1997, Buckel et al. 1999) and southern Africa (Blaber 1982, Martin \& Blaber 1983) show a substantial impact of several species of small piscivores on estuarine fish assemblages. For example, predation by young of the year bluefish Pomatomus saltatrix had a significant impact on recruitment strength of juvenile striped bass Morone saxatilis in the Hudson River estuary (Buckel et al. 1999). Despite such evidence, the assemblage of small potentially piscivorous fishes has been largely overlooked, particularly in the tropics.
There appears to be 2 reasons why small potential piscivores have been overlooked. Firstly, there is a common assumption that large piscivorous fishes will inflict greater mortality on prey fish populations than smaller piscivores because they are capable of consuming greater numbers of small juvenile fishes. However, there is a lack of dietary data supporting this proposition (e.g. Blaber 1980). Secondly, prey fish have generally been poorly defined, resulting in an equally vague definition of the relevant piscivore assemblage. Prey are rarely defined beyond 'small' or 'juvenile' fishes (e.g. Blaber 1980, Patterson \& Whitfield 2000) and with few exceptions (Scharf et al. 1997, Manderson et al. 1999, 2000), data on prey fish sizes are not presented. Considering that many 'small' prey fish may be adults of resident species such as gobiids (e.g. Blaber 1986) and that, in tropical estuaries, juvenile fishes range from $10 \mathrm{~mm}$ new recruits (Robertson \& Duke 1990b) to $>500 \mathrm{~mm}$ lutjanids and serranids (Sheaves 1995), a clearer definition than simply 'small' or 'juvenile' is required. It is logical to examine predation on new recruits because these experience the highest levels of natural mortality (Sogard 1997), and small changes in early mortality rates can profoundly influence ultimate cohort strength (Yanez-Arancibia et al. 1994). Consequently, predation on new recruits has the potential to be a major structuring force on estuarine nursery fish assemblages, as it is in other systems such as coral reefs (e.g. Hixon \& Carr 1997, Webster 2002, Webster \& Almany 2002).

Any examination of the piscivore assemblage important in structuring shallow estuarine nursery assemblages must include consideration of the full range of potential predators, along with detailed descriptions of the composition of the fish component of their diets. There is currently a paucity of data relating to these 2 components, particularly for shallow tropical estuarine habitats. The aim of this study was to gain an understanding of the range of piscivorous fishes that prey on newly recruited fish in shallow $(<1.5 \mathrm{~m})$ tropical estuarine nursery habitats. Two specific questions were addressed: (1) Which predatory fish present in shallow estuarine nurseries prey on other fishes? (2) What is the composition of the fish component of piscivore diets in terms of prey size and taxonomic identity? Once the predator assemblage has been identified, future research can examine the role of predation in structuring fish assemblages in tropical estuarine nurseries.

\section{MATERIALS AND METHODS}

Study sites and sampling. Fish were collected from 17 estuaries along a $250 \mathrm{~km}$ section of the coast of north Queensland, Australia (Fig. 1). Freshwater input to these estuaries is highly seasonal, with the climate 
Fig. 1. Estuarine sampling sites on the coast of northern Queensland, Australia

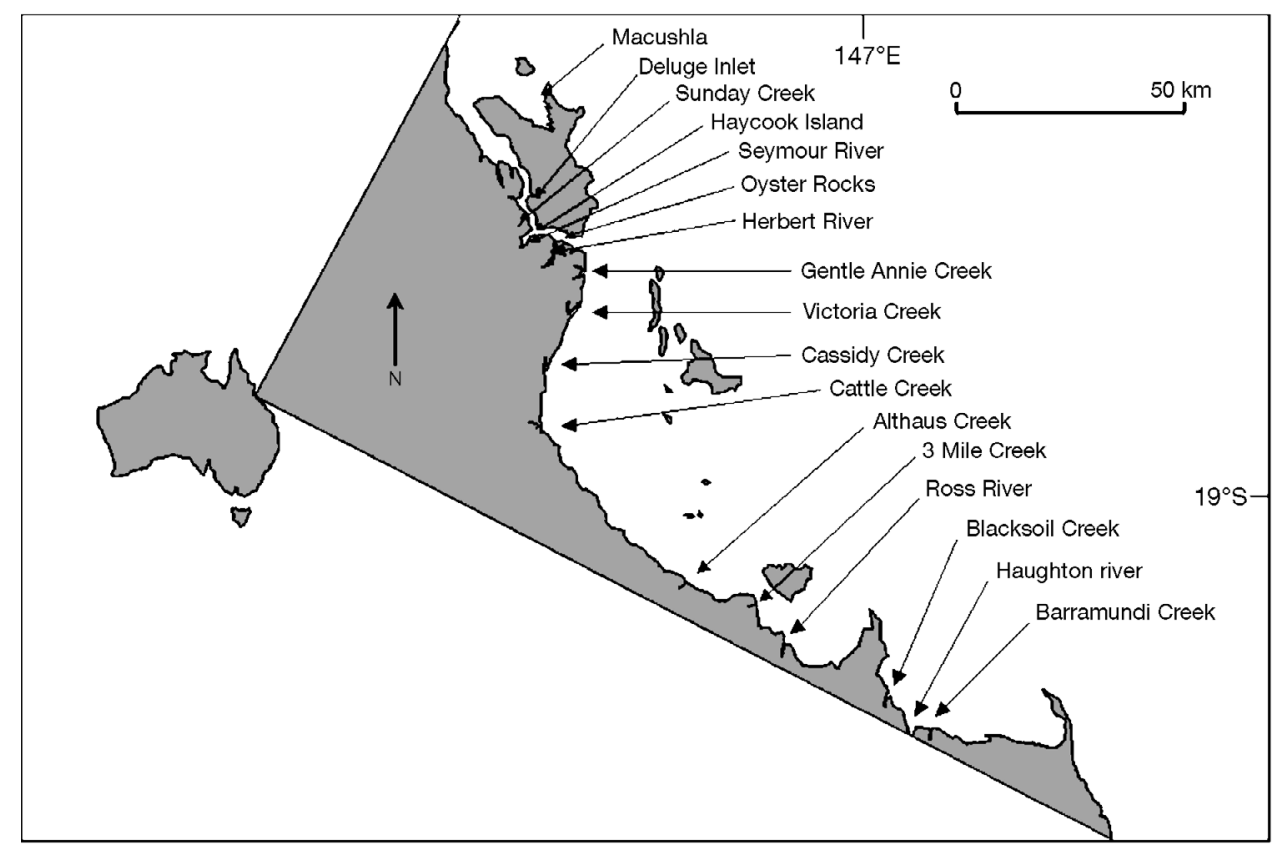

dominated by distinct summer-wet and winter-dry seasons. Maximum tidal range is ca. $4 \mathrm{~m}$ and extensive mixed mangrove forests are a feature of intertidal areas of estuaries throughout the region.

Sampling was conducted from July 1999 to January 2004. Sampling during recruitment periods would obviously be the most direct approach to determine which species prey on new recruits. However, as noted earlier, there is very little data on timing of recruitment of fishes into tropical estuaries in the Indo-West Pacific. What is available, indicates year-round recruitment, with individual species appearing at irregular and unpredictable times during extended recruitment seasons (Robertson \& Duke 1990b). Consequently, sampling effort was allocated as broadly as possible within the spatial and temporal limits of the study. Collections were made from the 17 estuaries on a total of 198 occasions, covering 35 of the 55 mo of the study. Collections included samples representing every month of the year, thus providing a broad-scale temporal and spatial profile of piscivore diets. Representative samples of fish were collected from shallow $(<1.5 \mathrm{~m})$, sandy habitats in the lower reaches $(\leq 5 \mathrm{~km})$ of each estuary using a combination of 6,12 and $25 \mathrm{~mm}$ mesh seine nets. Additional samples were collected from the same locations with beam trawls, gill nets, cast nets and angling with artificial lures, to ensure that broad ranges of sizes of predators were represented. Sampling concentrated on the lower reaches of the estuaries because these were the first shallow habitats available to new recruits entering the estuary. Although no published data are available on spatial patterns of fish recruitment within tropical estuarine systems, our observations indicate that most fish recruit to shallow waters in the lower reaches before dispersal throughout the system.

General diets. Not all taxa sampled were included in gut content analysis; taxa occurring only rarely in our samples, or those with known non-piscivorous diets (e.g. Mugilidae), were excluded. Fish for dietary analysis were chilled in an ice bath immediately upon capture to halt the decomposition of gut content, and frozen as soon as possible thereafter. In the laboratory, predators were identified, measured (fork length [FL] in $\mathrm{mm}$ ), weighed (wet weight in g) and their guts removed. Prey items were sorted and identified to as low a taxonomic level as possible. The presence of each prey type was recorded and the diets summarised as the frequency of occurrence of each prey type, that is, the percentage of total individuals within a size class or taxon that contained a particular prey (Hyslop 1980). Individuals with empty guts were not included in frequency of occurrence calculations. The prey category 'shrimp' includes unidentifiable shrimp-like crustacea, as well as alpheids, palaemonids and mysids. 'Other crustacea' includes a small number of crustaceans not defined in alternate categories, as well as highly digested crustacea, and as such may also include prey from the defined crustacean categories. The category 'other' includes a small number of prey types not defined in alternate categories. Unidentifiable tissue was only recorded (as 'other') when it was the only food present in the gut.

Major and minor piscivores. Initially, fish were categorised as 'major' or 'minor' piscivores using least squares univariate classification and regression tree (CART) analysis based on the occurrence of fish in the 
diets (De'ath \& Fabricius 2000). Previous authors have categorised predators as major piscivores if fish occur in more than $50 \%$ of individuals (Whitfield \& Blaber 1978); however, univariate CART analysis provides a more objective method for categorising members of the piscivore assemblage. The technique successively splits the data into increasingly homogeneous groups, by minimising the residual sums of squares for each split, analogous to least squares regression (De'ath \& Fabricius 2000). In the current analysis, the residuals equal the difference between the overall average occurrence of fish across all taxa within a group and the occurrence of fish in the diet of each individual taxon. The 'best' tree model was chosen by bootstrapped V-fold cross validation using the Min. + 1SE rule (Breiman et al. 1984). Major piscivores identified by tree analysis and with samples sizes $>35$ were included in further analysis.

Trends and similarities in piscivore diets. Individual fish from each taxon were grouped into broad size classes using a series of non-metric multidimensional scaling (nMDS) analyses (1 for each taxon) based on diet. For each taxon, fish were initially grouped into $5 \mathrm{~mm}$ size classes. Where necessary, adjacent size classes were pooled to provide sufficient sample sizes per size class for analysis, while maintaining as much size resolution as possible. Apparent broad size classes identified by the individual species nMDS solutions were confirmed via hierarchical cluster analysis based on the same Bray-Curtis distance matrices used for each nMDS analysis. If analyses failed to identify discrete groupings because of some continuous trend in the diet across the size classes, equal size class groupings were made.

Once species had been split into broad size classes, all species were combined into a single data set. Similarities and trends in the diets of the abundant major piscivores were examined using nMDS, based on BrayCurtis dissimilarities calculated from the frequency of occurrence of each prey category in each size group of each taxon. Where the multi-species nMDS identified groups of taxa with similar diets, ontogenetic dietary models are only presented for a representative taxon from each group, rather than presenting multiple figures describing similar diets. Dietary models that detail ontogenetic trends in the diets of the major piscivores were produced using the lowess smoothing function (Cleveland 1979) on the frequency of occurrence of each prey type across the original fine size classes used in the individual species nMDS.

Prey fish size and identity. Where possible, fish prey were identified and measured (FL [mm]). In the case of highly digested fish prey, fish were identified to the lowest taxon possible from otoliths in the guts using a catalogue of photographs of the sagittal otoliths of common coastal and estuarine fishes from the region (R. Baker unpubl. data). The sizes of digested prey fishes were estimated using otolith weight-fish length relationships calculated from prey fishes collected from the same estuaries. Where prey fishes were only identifiable to genus or family, regressions combining all data for that genus or family were used to estimate prey size. $\mathrm{R}^{2}$ values ranged from 0.84 to 0.99 for species-level regressions, and from 0.90 to 0.98 for genera and families.

Prey fish otoliths exposed to acidic digestive fluids in the stomachs of piscivores gradually erode and thus, those exposed for long periods ( $>2 \mathrm{~h}$ ) may be unreliable for estimating prey size (Jobling \& Breiby 1986). Consequently, the following precautions and validations were undertaken: (1) otoliths showing obvious signs of digestion such as loss of fine structural details were not used to estimate prey length, (2) comparison of length estimates and measurements from 27 fish prey in advanced stages of digestion and not morphologically identifiable, yet sufficiently intact to obtain length measurements, and with otoliths still encased within the otic capsule, revealed a high degree of accuracy in the length estimates from these prey (estimated length $=1.02 \times$ measured length, $\mathrm{R}^{2}=0.93$ ), (3) there was little difference between the upper and lower boundaries of the predator-prey length relationships described by quantile regression (see below) for scatter plots including and excluding prey lengths estimated from otoliths free of the otic capsule but showing no signs of digestion. Estimates of fish prey length from otoliths encased in the otic capsule, or exposed to but showing no signs of digestion, were thus considered reliable and were included in the predator-prey length relationships.

The boundaries of the predator-prey length relationships were described by least absolute values quantile regression (Scharf et al. 1998). The boundaries were represented by the 90th and 10th quantiles as these provided consistent parameter estimates for sample sizes presented in this study (Scharf et al. 1998). Quantile regression coefficient standard errors were estimated using 20 iterations of the bootstrap resampling technique described by Gould (1992).

\section{RESULTS}

\section{General diets}

A total of 69 fish taxa were sampled and examined for gut contents. Of these, 51 taxa from 21 families had fish in their diets (Table 1). The combined sample of the 51 taxa included 4985 individuals that contained food in the stomach. Of the 51 taxa, 19 had sample sizes of 10 or less. 


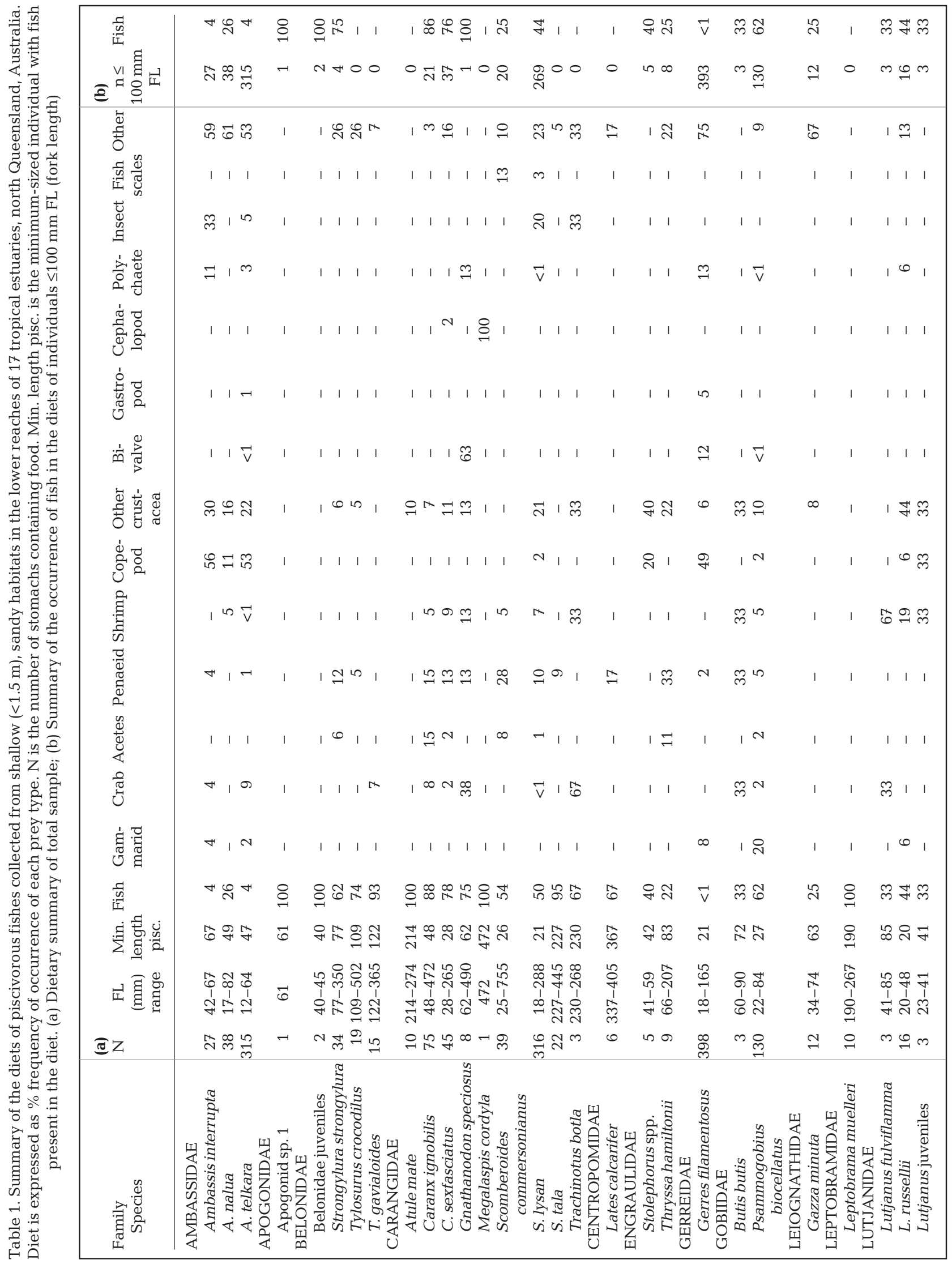




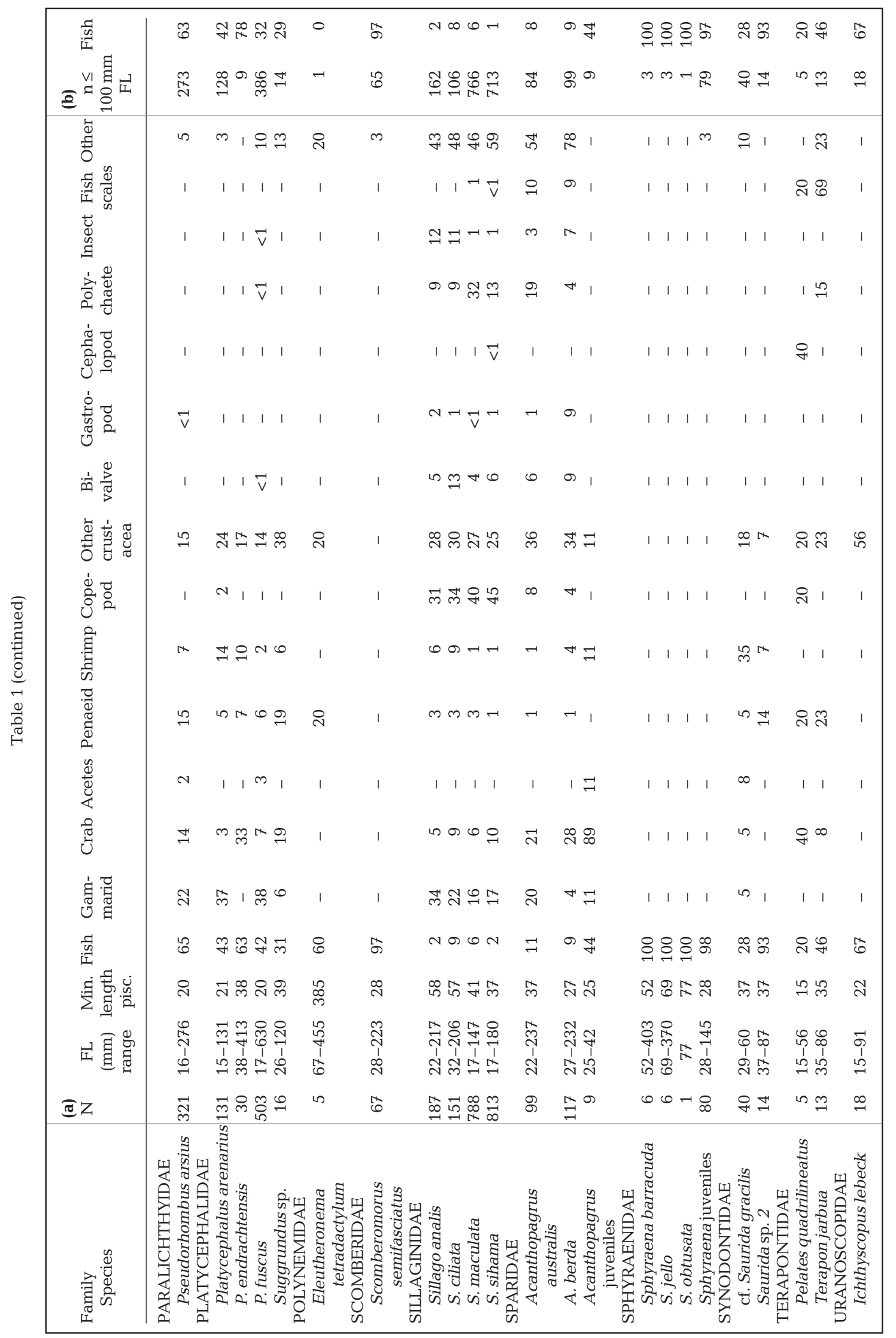


The non-piscivorous taxa were dominated by Leiognathus spp. (Leiognathidae). Details of the diets of the minor- and non-piscivorous fishes will be published elsewhere. Taxa that preyed heavily on fish were either exclusively piscivorous (Sphyraenidae and Scomberidae) or also consumed other mobile epibenthic/nektonic prey, mainly crustacea (e.g. Carangidae, Platycephalidae) (Table 1). Only 2 individual Sphyraena juveniles and 2 Scomberomorus semifasciatus were recorded with anything other than fish in their guts, and each of these contained unidentifiable prey that was probably fish remains. Those taxa for which fish occurred only infrequently in the diet, were primarily either planktivorous (e.g. Ambassidae) or benthic invertebrate feeders (e.g. Sillaginidae, Sparidae) (Table 1).

In 25 of the 51 taxa, the smallest individuals examined had consumed fish (Table 1a). Forty-two taxa had a minimum length of piscivory $<100 \mathrm{~mm}$; for 29 of these it was $<50 \mathrm{~mm}$. The smallest individual with fish in the stomach was a $15 \mathrm{~mm}$ FL Pelates quadrilineatus. Although 9 taxa had a minimum length of piscivory $>100 \mathrm{~mm}$, the combined sample of these 9 taxa only included 1 individual $<100 \mathrm{~mm}$ (Eleutheronema tetradactylum, $\mathrm{n}=5, \mathrm{n}<100 \mathrm{~mm}=1$; Table 1b). Fish was the dominant prey in the diets of all 9 taxa with minimum lengths of piscivory $>100 \mathrm{~mm}$ (Table 1a).

\section{Major and minor piscivores}

There were 2 main groups within the piscivore assemblage based on the occurrence of fish in the diet (Fig. 2). Minor piscivores comprised 3015 individuals in 15 taxa, with a combined average occurrence of fish
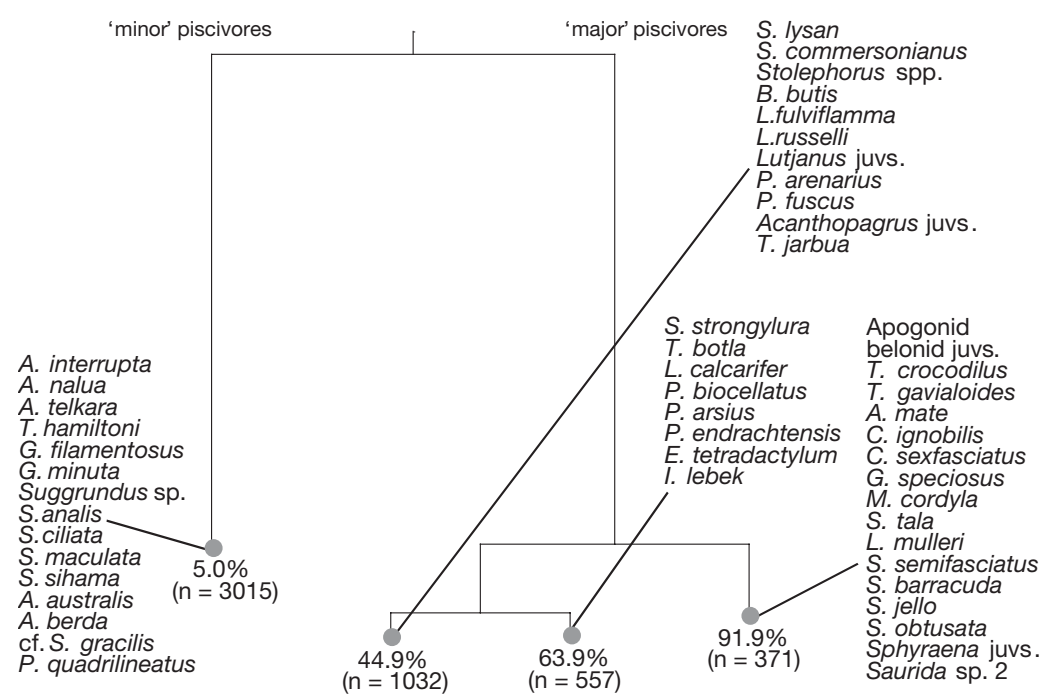

Fig. 2. Four-leaf univariate classification and regression tree defining major and minor piscivores based on the occurrence of fish in the diet. Sample sizes and average occurrence of fish within each group are shown below each leaf of $5 \%$. The remaining 1970 individuals in 36 taxa formed the major piscivores. These were further divided into 3 groups in the best CART model; however, most of the variability in the data set was explained by the first split, as shown by the relative lengths of the vertical branches of the tree (De'ath \& Fabricius 2000). Suggrundus sp. had the highest occurrence of fish of any of the minor piscivores, with $31 \%$ of individuals containing fish, while Butis butis, with $33 \%$, had the lowest occurrence of fish prey among the major piscivores (Table 1a). Major piscivores with sample sizes $>35$ were included in further analysis. These were Caranx ignobilis, C. sexfasciatus, Scomberoides commersonianus, S. lysan (Carangidae), Psammogobius biocellatus (Gobiidae), Pseudorhombus arsius (Paralichthyidae), Platycephalus arenarius, P. fuscus (Platycephalidae), Scomberomorus semifasciatus (Scomberidae) and Sphyraena juveniles (Sphyraenidae). Three species of barracuda, Sphyraena barracuda, $S$. jello and $S$. obtusata were pooled with Sphyraena juveniles for further analysis because of the similarity in diets; the only identifiable prey in any Sphyraena spp. was fish (Table 1a).

Samples of the 10 abundant major piscivores included a broad range of sizes (Fig. 3). The fine size classes along the $x$-axis in Fig. 3 are those used in the individual species nMDS and in the smoothed ontogeny models. The dotted lines indicate the broad size classes used in the multi-species nMDS, as identified by the individual species nMDS and hierarchical cluster analysis. Neither Sphyraena spp. (Fig. 3i) nor Scomberomorus semifasciatus (Fig. 3j) showed any size-related trends in dietary composition, with virtually all individuals consuming only fish (Table 1); thus, the lack of broad size class divisions for the multi species nMDS analysis. The 2 individual $S$. semifasciatus $>100 \mathrm{~mm}$ (Fig. 3j) were 213 and $223 \mathrm{~mm}$ FL.

\section{Trends and similarities in piscivore diets}

Several of the abundant major piscivores showed ontogenetic shifts in relation to the contribution of fish in their diets, while others consumed fish at all sizes examined (Fig. 4a). Platycephalus fuscus, $P$. arenarius and Pseudorhombus arsius all had similar diets showing an ontogenetic shift from preying primarily on gammarid amphipods at small sizes to preying on fish at larger sizes (Fig. 4b, Group i \& Fig. 5a). Psammogobius biocellatus, Scomberoides commersoni- 
a) Platycephalus arenarius, $\mathrm{n}=131$

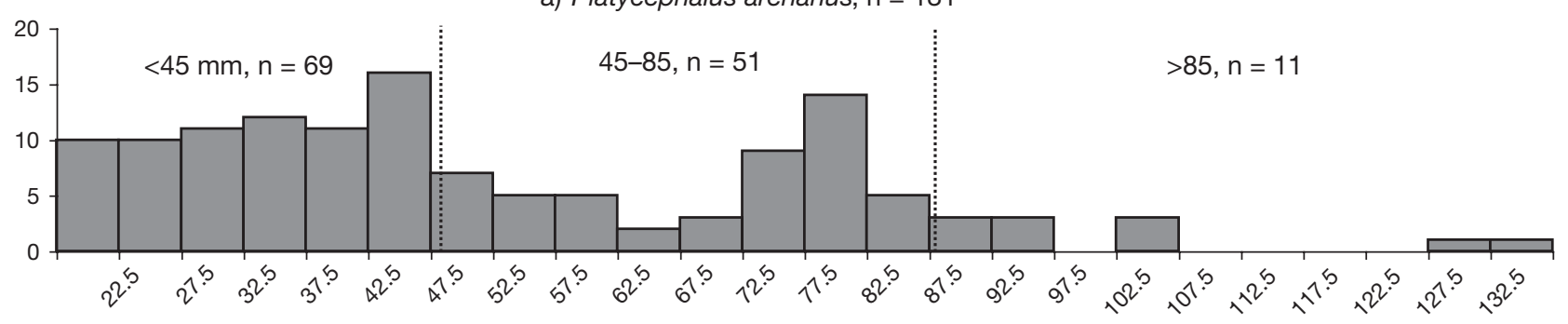

b) Platycephalus fuscus, $\mathrm{n}=503$

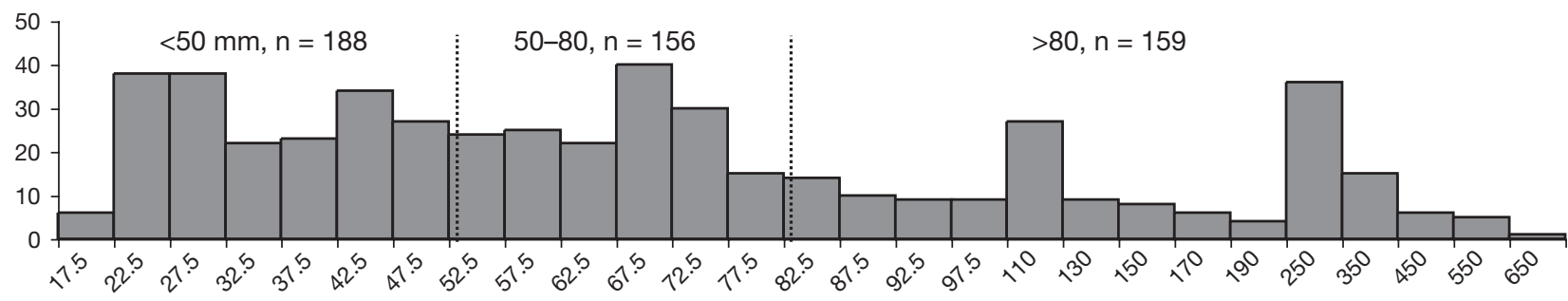

$<30 \mathrm{~mm}, \mathrm{n}=39$

c) Pseudorhombus arsius, $\mathrm{n}=321$

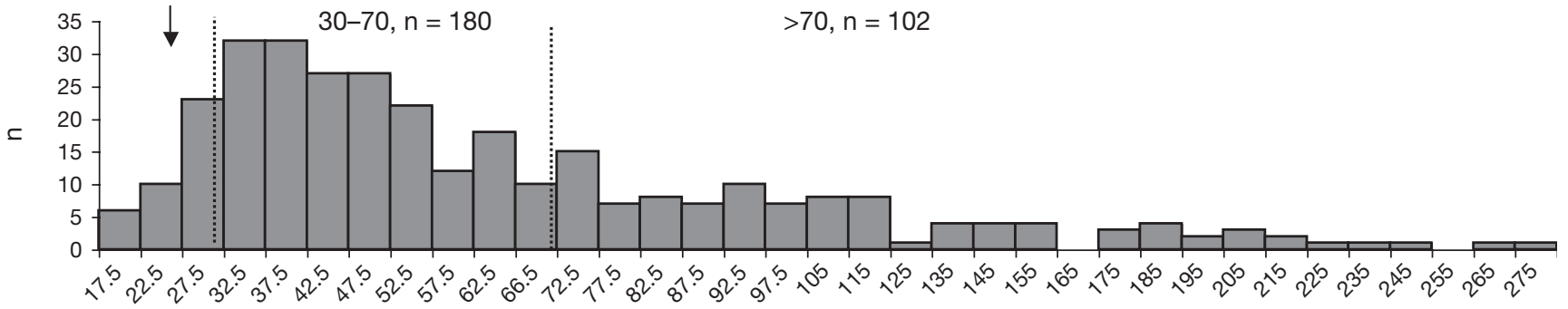

d) Psammogobius biocellatus, $\mathrm{n}=130$
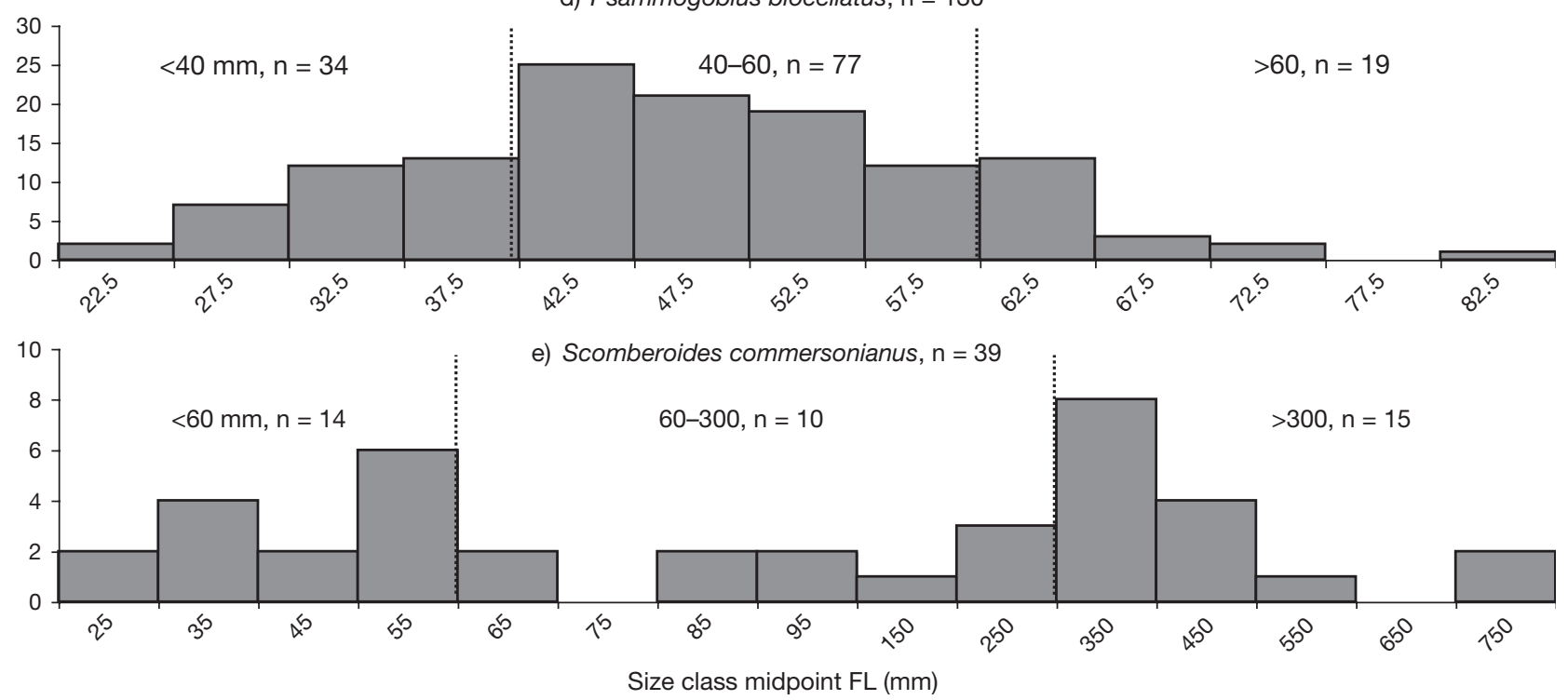

Fig. 3. (above and facing page) Size structure of samples of the abundant major piscivores used in further dietary analysis. Note that the size class widths are not constant in (b), (c), (e), (f), (h), (i) and (j). For example, the size structure of the Platycephalus fuscus sample is presented in $5 \mathrm{~mm}$ size classes from 15 to $100 \mathrm{~mm}, 20 \mathrm{~mm}$ size classes from 100 to $200 \mathrm{~mm}$ and $100 \mathrm{~mm}$ size classes from 200 to $700 \mathrm{~mm}$ (Fig. 3b). Broad size classes used in the multispecies nMDS are indicated by dotted lines and sample size for each of these size classes is provided. For example, nMDS and cluster analysis on the diet of $P$. fuscus revealed 3 broad size classes: $<50 \mathrm{~mm}(\mathrm{n}=188), 50$ to $80 \mathrm{~mm}(\mathrm{n}=156)$ and $>80 \mathrm{~mm}(\mathrm{n}=159)$ (Fig. $3 \mathrm{~b})$ 
f) Scomberoides lysan, $n=316$

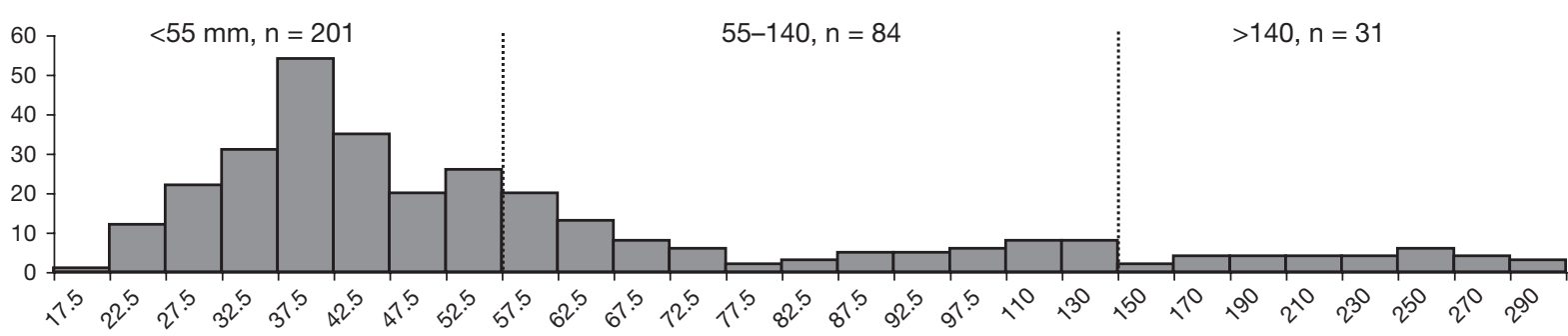

g) Caranx ignobilis, $\mathrm{n}=75$

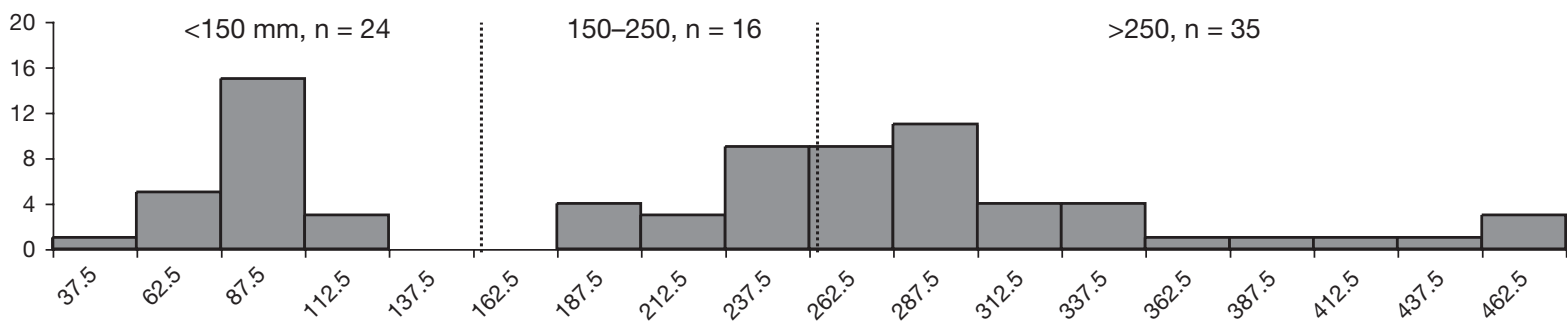

h) Caranx sexfasciatus, $n=45$
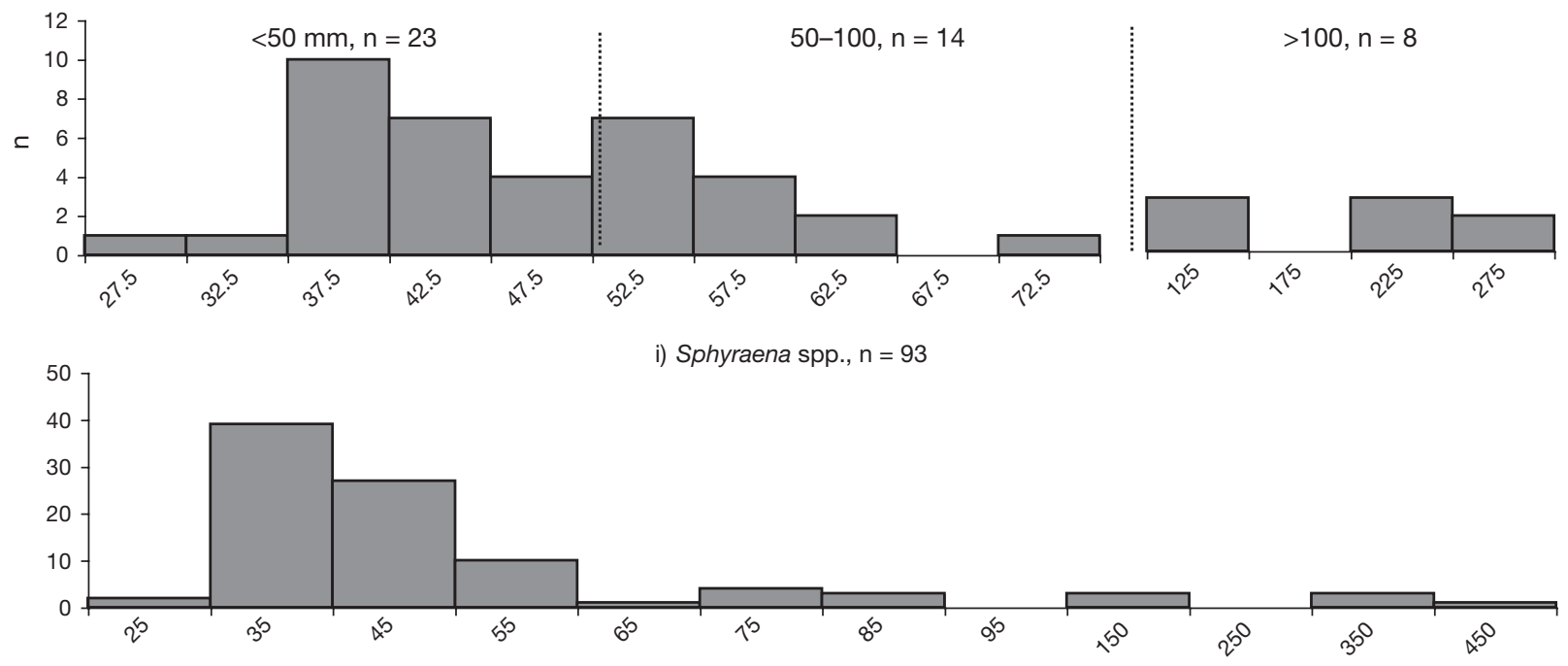

j) Scomberomorus semifasciatus, $n=67$

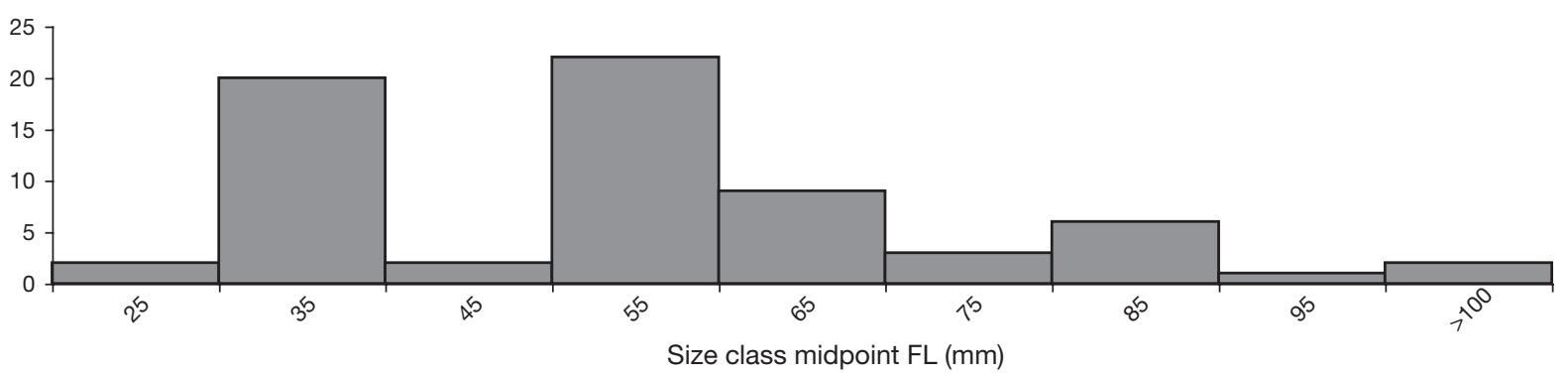

anus and S. lysan showed a similar ontogenetic shift, preying mainly on fish at larger sizes; however, small individuals of these taxa preyed mainly on penaeids and/or other crustacea (Fig. 4b, Group ii \& Fig. 5b). In contrast to $P$. biocellatus and $S$. commersonianus, insects were a prominent part of the diet of small S. lysan (Fig. 5b): otherwise, their diets were similar (Fig. 4a). Fish was dominant in the diet of Caranx ignobilis and $C$. sexfasciatus at all sizes examined, with smaller contributions of penaeids and other crustacea (Fig. 4b, Group iii 


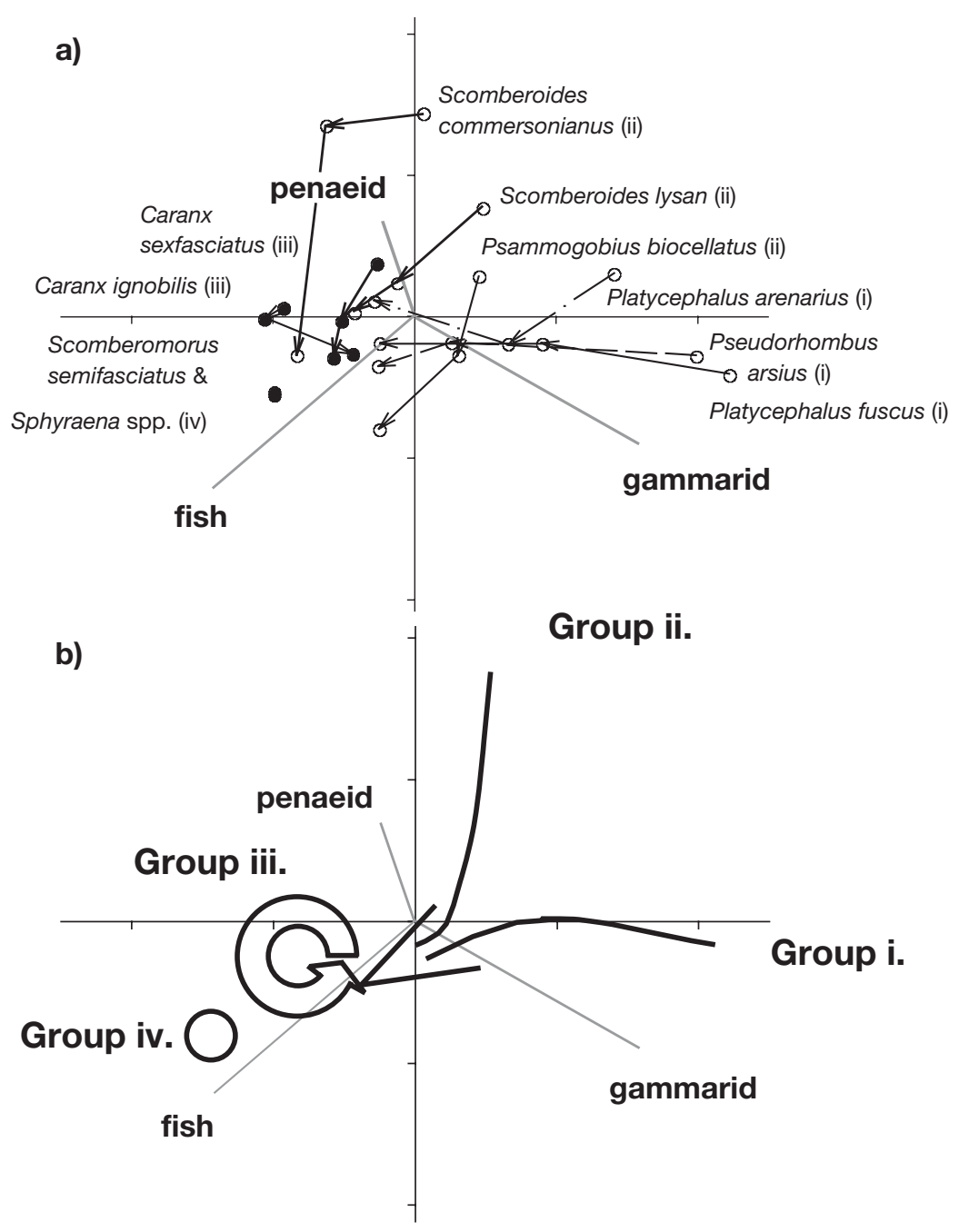

Fig. 4. Dietary trends in the piscivore assemblage. (a) Two-dimensional nMDS solution using Bray-Curtis dissimilarities calculated from the frequency of occurrence of diet categories, stress $=0.11$. Arrows link small to large broad size classes demarcated by dotted lines in Fig. 3. Vectors indicate the correlation of the original variables (prey categories) with the 2-dimensional space. Lengths of vectors are proportional to the partial $\mathrm{R}^{2}$. Only prey categories with partial $\mathrm{R}^{2}>$ 0.35 are presented; fish 0.93, gammarid 0.91, penaeid 0.36. (b) Simplified representation of groupings of major piscivores. Group identities are shown in parentheses in Fig. 4a

\& Fig. 5c). Scomberomorus semifasciatus and Sphyraena spp. consumed fish almost exclusively (Fig. 4b, Group iv \& Fig. 5d).

\section{Prey fish size and identity}

The piscivore assemblage consumed a range of fish prey, with small juvenile Leiognathus spp., Sillago spp. and Gerres filamentosus common in the diets of most of the abundant major piscivores (Fig. 6). The gobid Acentrogobius viridipunctatus was another common small fish prey, present in the diets of all the abundant major piscivores except Scomberoides commersonianus. The 4 prey taxa listed above were common in the diets of most of the other piscivores examined (Table 1). Additionally, clupeoid fishes (including Stolephorus spp., Herklotsichthys spp., Sardinella spp. and unidentified clupeoids) were prominent in the diets of the carangids (e.g. Fig. 6e-h). Many of the prey fish present in the smaller piscivores $(<50 \mathrm{~mm})$ were larvae or small new recruits that were unidentifiable due to a lack of distinguishing morphological features of the partially digested prey fish at these small sizes (e.g. Fig. 6a).

Seven identifiable fish prey consumed by the 3 Sphyraena spp. >120 mm FL and the 1 identifiable fish in the stomach of the $213 \mathrm{~mm}$ Scomberomorus semifasciatus were neither included in quantile regressions (Table 2) nor presented in the predator-prey size relationships (Fig. 6i,j). For Sphyraena spp. >120 mm, both the largest (155 mm clupeid in a $370 \mathrm{~mm}$ Sphyraena jello) and the smallest (32 mm Ambassis telkara in a $394 \mathrm{~mm}$ Sphyraena barracuda) of the 7 prey were highly influential points in the quantile regressions, such that the 90th, 95th, 99th and the 10th, 5th and 1st quantiles all passed through the upper and lower points, respectively. Inclusion of the prey-size data for the 3 Sphyraena spp. $>120 \mathrm{~mm}$ in the scatter plots compacted the bulk of the data, making the composition and boundaries of prey consumed by Sphyraena spp. <120 mm FL uninterpretable (Fig. 6i). Similarly, the 1 identifiable fish in the stomachs of S. semifasciatus $>100 \mathrm{~mm}$, a $48 \mathrm{~mm}$ Leiognathus spp. in a $213 \mathrm{~mm}$ S. semifasciatus, was excluded from quantile regression and the scatter plot (Fig. 6j).

The largest individual Platycephalus fuscus, Pseudorhombus arsius, Scomberoides commersonianus, Sphyraena spp. and Scomberomorus semifasciatus did not consume small new recruits, while the remaining major piscivores consumed small fish across the entire size range examined (Fig. 6, Table 2). Large Scomberoides lysan, Caranx ignobilis and C. sexfasciatus individuals consumed small fish prey, close to the smallest fish consumed by any individual of these species (Fig. 6f-h). The relatively constant minimum prey size is reflected by the low slope estimates for the lower bound- 

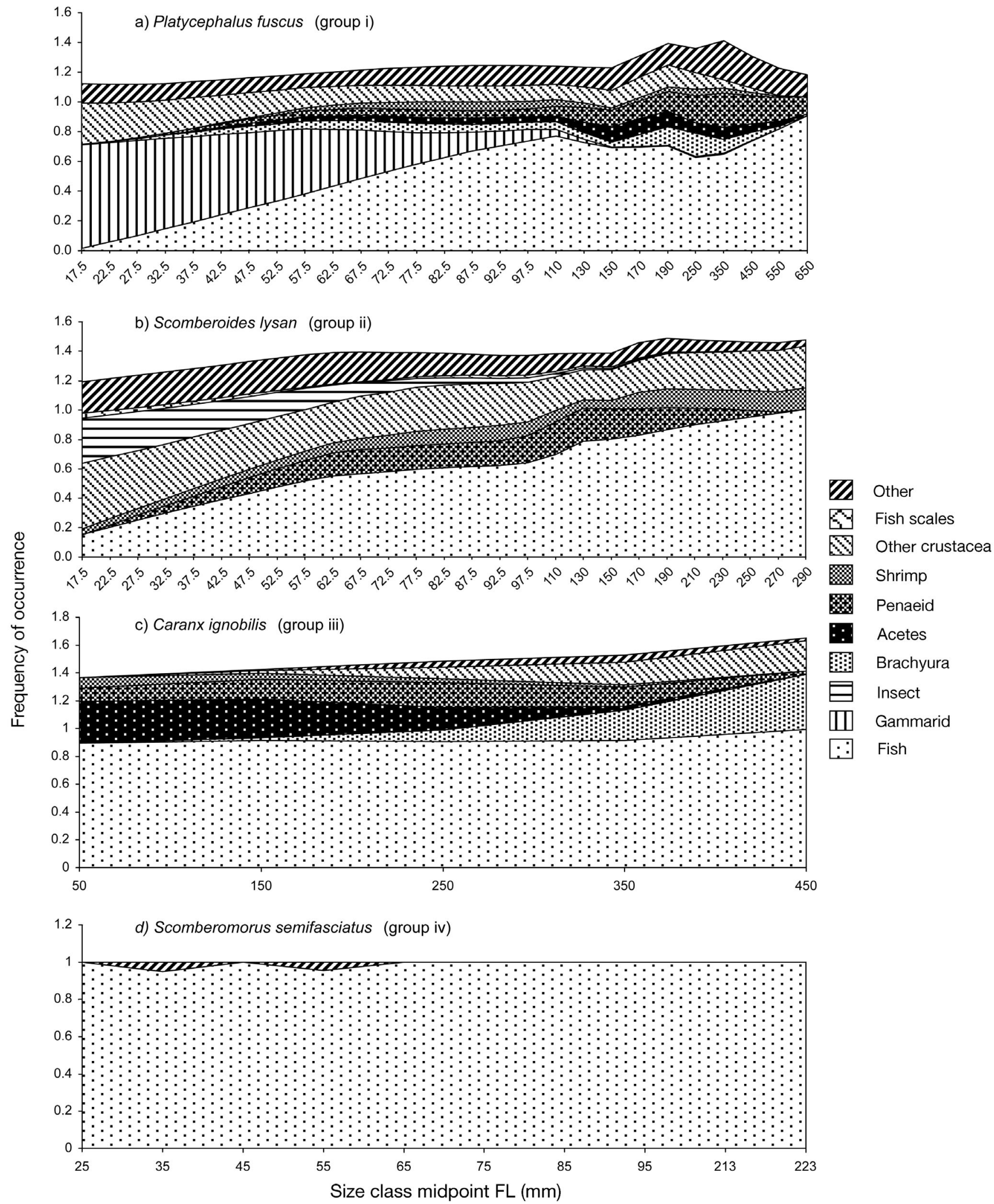

Fig. 5. Representative ontogenetic dietary models for each of the 4 groups of major piscivores identified by nMDS. Raw data were lowess smoothed with smoothing factors (a) 0.7 , (b) 0.7 , (c) 0.9 , (d) not smoothed 

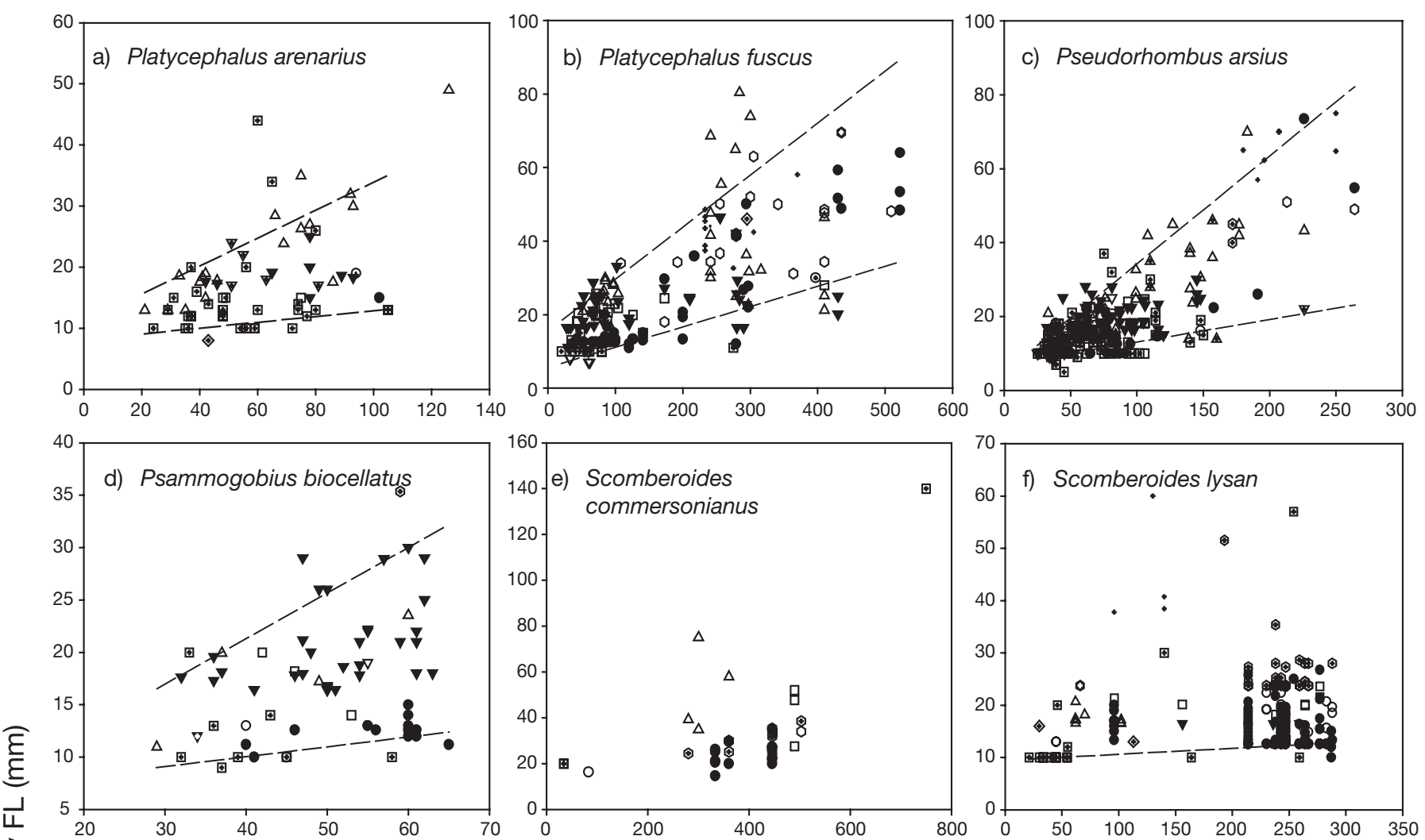

(1)
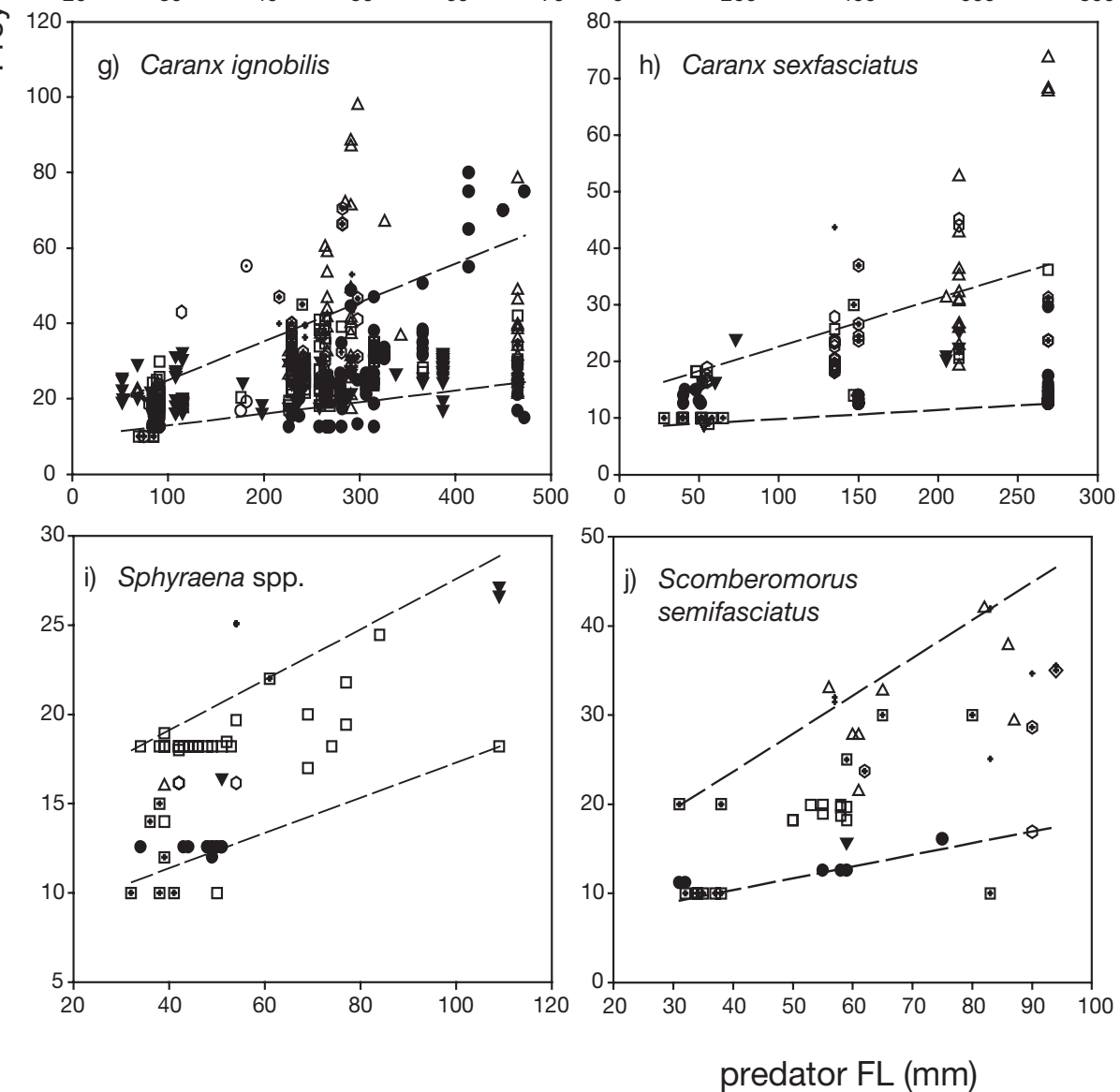

Fig. 6. Size and taxonomic identity of fish prey in the diets of the abundant major piscivores. Dashed lines represent significant slope estimates for the upper (90th quantile) and lower (10th quantile) boundaries as determined by quantile regression 
Table 2. Slope estimates $( \pm \mathrm{SE})$ for the upper (90th quantile) and lower (10th quantile) boundaries of predator-prey length relationships of the abundant major piscivores, as determined by quantile regression. $\mathrm{n}=$ number of fish prey shown in Fig. 6 and used in quantile regression. NS (not significant): p > 0.05; ${ }^{*} \mathrm{p}<0.05 ;{ }^{* *} \mathrm{p}<0.01 ;{ }^{* * *} \mathrm{p}<0.001 ;-$ insufficient data for analysis

\begin{tabular}{|c|c|c|c|}
\hline \multirow{2}{*}{ Taxon } & \multirow[b]{2}{*}{$\mathrm{n}$} & \multirow[b]{2}{*}{ 10th } & \multirow[b]{2}{*}{ 90th } \\
\hline & & & \\
\hline Platycephalus arenarius & 72 & $0.057 \pm 0.004^{* * *}$ & $0.227 \pm 0.014^{* * *}$ \\
\hline$P$. fuscus & 180 & $0.041 \pm 0.002^{* * *}$ & $0.131 \pm 0.003^{* * *}$ \\
\hline Pseudorhombus arsius & 306 & $0.060 \pm 0.003^{* * *}$ & $0.292 \pm 0.006^{* * *}$ \\
\hline Psammogobius biocellatus & 71 & $0.092 \pm 0.007^{* * *}$ & $0.432 \pm 0.024^{* * *}$ \\
\hline Scomberoides commersonianus & 35 & - & - \\
\hline S. lysan & 258 & $0.011 \pm<0.001^{* * *}$ & NS \\
\hline Caranx ignobilis & 536 & $0.031 \pm 0.001^{* * *}$ & $0.104 \pm 0.005^{* * *}$ \\
\hline C. sexfasciatus & 176 & $0.016 \pm<0.001^{* * *}$ & $0.085 \pm 0.006^{* * *}$ \\
\hline Sphyraena spp. & 62 & $0.097 \pm 0.014^{* * *}$ & $0.140 \pm 0.031^{* * *}$ \\
\hline Scomberomorus semifasciatus & 48 & $0.122 \pm 0.018^{* * *}$ & $0.422 \pm 0.019^{* * *}$ \\
\hline
\end{tabular}

of taxa over a broad range of sizes. Individuals consuming fish ranged in size from a $15 \mathrm{~mm}$ Pelates quadrilineatus up to a $755 \mathrm{~mm}$ Scomberoides commersonianus (Table 1). Only 9 taxa had a minimum length of piscivory $>100$ $\mathrm{mm}$. These taxa had small sample sizes ( $\mathrm{n} \leq 22$ ) and the combined sample included only 1 individual $<100 \mathrm{~mm}$. All 9 were categorised as major piscivores, with fish dominating their diets; so, despite the small sample sizes, it seems likely that smaller individuals of these taxa would be piscivorous to some degree. Based on average predator-prey length ratios reported in the literature on piscivory, Sheaves (2001) demonstrated that new recruits of 15 to

aries (10th quantile) of the predator-prey size relationships, as estimated by quantile regression (Fig. 6f-h, Table 2). The trend for these species to consume relatively small fish prey is also shown by the low (C. ignobilis, C. sexfasciatus) or non-significant (S. lysan) slope estimates for the upper boundaries (90th quantile) of the predator-prey size relationships (Fig. 6f-h, Table 2). These species mainly consumed fish prey much smaller than the maximum size they are capable of ingesting, as indicated by the spread of data above the upper boundary (Fig. 6g,h). In contrast, the remaining piscivores regularly consumed fish prey close to the maximum size recorded (Fig. 6a-d,i,j). These piscivores showed an increase in both the maximum and minimum fish prey size consumed (Fig. $6 a-d, i, j$, Table 2), and the slopes of their lower boundaries were similar to the slopes of the upper boundaries of the carangids (Table 2). Psammogobius biocellatus and Scomberomorus semifasciatus consumed fish prey that were large relative to the predator's body size (Table 2), including several prey that were greater than $50 \%$ of the predators length (Fig. 6d,j). The sample size of fish from the diet of $S$. commersonianus was too small to analyse using quantile regression; however, the expected positive relationship between predator and prey size is apparent (Fig. 6e). The dense vertical stacks in the predator-prey relationships for Scomberoides lysan, Caranx ignobilis and C. sexfasciatus indicate the consumption of large numbers of fish by individual predators (Fig. $6 \mathrm{f}-\mathrm{h}$ ). Individuals of the other abundant major piscivores tended to consume fewer prey per predator (Fig. 6a-e,i,j).

\section{DISCUSSION}

The piscivore assemblage of the shallow estuarine habitats sampled in this study included a diverse range
$25 \mathrm{~mm}$ would be vulnerable to predators between 38 and $64 \mathrm{~mm}$. In the present study, the majority of taxa contained individuals that were piscivorous at these or smaller sizes. Many piscivores were much smaller than those previously considered as potentially important predators in estuarine nurseries (e.g. Salini et al. 1990, Patterson \& Whitfield 2000). The piscivore assemblage included both small species (e.g. Psammogobius biocellatus) and small juveniles of species for which larger individuals have been considered important piscivores elsewhere (e.g. S. commersonianus, Salini et al. 1990). The proposition that shallow water habitats in tropical estuaries provide small juvenile fishes with refuge from predation because there are few large piscivorous fishes (e.g. Blaber 1980), fails to recognise the importance of the many small piscivores present in these habitats.

\section{Sampling design}

As with many previous studies (eg. Salini et al. 1990, Haywood et al. 1998), the dietary data presented here are pooled across fish collected from many locations on many occasions. This has several implications in relation to the interpretation of the dietary models presented, and their overall relevance to the importance of piscivory in shallow estuarine nurseries. Data pooled across sampling times and locations provides no information on temporal and spatial patterns in dietary habits. Information on diet variability is important in understanding the influence of processes such as prey availability, prey selectivity and the co-occurrence of predators and prey, all of which contribute to complex predator-prey dynamics that structure fish assemblages (e.g. Juanes \& Conover 1995, Juanes et al. 2001). However, such processes cannot be examined 
without first having a clear understanding of the relevant assemblage of predators and prey. Given our lack of basic knowledge of the diverse fish faunas of tropical estuarine systems (Blaber 2000), the aim of this paper was not to examine spatial and temporal patterns in predation dynamics, but rather to identify the relevant piscivore assemblage as a baseline from which to examine these patterns in the future. Consequently, the dietary data presented here should not be interpreted beyond being a general representation of the dietary habits of members of the shallow-water tropical estuarine fish assemblage.

Early mortality rates can have a major influence on ultimate cohort strength (Yanez-Arancibia et al. 1994), and predation on small fish during and shortly after their recruitment to shallow estuarine nurseries may be significant in structuring estuarine fish assemblages. Predation on newly settled fish is a major structuring force on coral reef fish communities (e.g. Carr \& Hixon 1995, Hixon \& Carr 1997, Webster \& Almany 2002), and in extreme cases, has the potential to cause recruitment failure (Webster 2002). This paper identifies a range of piscivores that consume small fish using shallow estuarine nursery grounds. As recruits appear in the nursery all year-round, with patchy recruitment within broad seasons for individual taxa (Robertson \& Duke 1990b), allocating sampling effort as widely as possible was a logical approach to gaining insight into the range of potentially important piscivores in shallow tropical estuarine nurseries. Importantly, this sampling design would underestimate the level of impact of various piscivores on new recruits because the patchy nature of recruitment means that the data presented include samples of predators from times when new recruits were not available. What the design does allow is an overview of the piscivore assemblage that prey on new recruits. It also provides insight on the range of strategies within the piscivore assemblage.

\section{Major and minor piscivores}

Of the piscivore taxa, 19 ( 2 minor and 17 major piscivores) had sample sizes of 10 or less (Fig. 2, Table 1). Such small sample sizes may not adequately represent a species diet and consequently, the classifications of taxa with small sample sizes as major or minor piscivores should be interpreted with caution. It is possible that with larger samples of these taxa, some of the major piscivores would have been classified as minor piscivores and vice versa.

While the major piscivores described here and elsewhere are likely to be important predators simply because they consume fish most of the time, the minor piscivores may also play an important role in structur- ing shallow water nursery assemblages. Many of the minor piscivore taxa, such as the ambassids, engraulids and sillaginids, dominate the shallow water fish communities of tropical Indo-West Pacific estuaries (Blaber 1980, Blaber et al. 1985, 1989, Robertson \& Duke 1987, 1990a). Martin \& Blaber (1983) concluded that small Ambassis spp. in southern African estuaries were at least as significant a group of predators as the larger, primarily piscivorous fishes. This is because although fish were rarely dominant in the diet, periodic predation on fish eggs and fry during spawning and recruitment periods, combined with the high abundances of Ambassis spp., resulted in a great potential of these mainly planktivorous fishes to impact fish recruitment strength (Martin \& Blaber 1983).

When the abundance of various piscivores is considered, it becomes clear that the relative contribution of fish to the diets does not necessarily reflect the relative importance of each piscivore. One of the species studied by Martin \& Blaber (1983), Ambassis gymnocephalus (called A. telkara in this study, Komori 2001), has been recorded as highly abundant in estuaries along the north coast of Australia (Blaber et al. 1985, 1989), and NE Queensland (Robertson \& Duke 1987, 1990a,b). For example, A. telkara constituted $29.3 \%$ by numbers and dominated the biomass of the shallow water fish fauna from Alligator Creek near Townsville, Australia (Robertson \& Duke 1990a,b). Even if the average occurrence of fish in the diet ( $4 \%$ in this study) represents the level of predation by these on juvenile fish recruiting to the nursery, such that only $4 \%$ of individual $A$. telkara were piscivorous during a recruitment event, piscivorous ambassids alone would outnumber the combined assemblage of major piscivores recorded by Robertson \& Duke (1990a). Many of the juvenile fish utilising shallow nursery habitats in tropical estuaries are minor piscivores (e.g. Salini et al. 1990, Haywood et al. 1998, this study), yet their potential impact on nursery fish assemblages has not previously been discussed. Given the probability that the average low occurrence of fish in the diets of many minor piscivores represents switching from alternate prey to briefly targeting new recruits during recruitment events (Martin \& Blaber 1983), new recruits entering shallow tropical estuarine nurseries would encounter far more predatory 'minor' piscivores than large primarily piscivorous fish. The combined mortality inflicted by minor piscivores could be significant in structuring tropical estuarine nursery fish assemblages and is worthy of further investigation.

\section{Trends and similarities in piscivore diets}

There are several patterns of ontogenetic changes in the contribution of fish in the diet of piscivores exam- 
ined in this study. Minor piscivores, by definition, have a low frequency of occurrence of fish in their diets, and no clear relationship between predator size and the occurrence of fish was apparent. The low occurrence of fish in the diets of minor piscivores represents either some constant low level of consumption of fish prey, or switching from alternate prey to target new recruits during recruitment events (see discussion of 'Major and minor piscivores'). Among the major piscivores, some taxa showed ontogenetic shifts from alternate prey to fish with increasing predator size; for others, fish dominated the diets at all sizes examined (Fig. 4). Caranx ignobilis and C. sexfasciatus may undergo ontogenetic dietary shifts at sizes smaller than sampled in this study; however, these were primarily piscivorous across all sizes sampled (Figs. 4 \& 5c).

The range of predation strategies coupled with extended spawning seasons and irregular recruitment pulses of both predator and prey (Robertson \& Duke 1990b), result in a complex mosaic of co-occurrence of predators and prey, making it difficult to predict the exact assemblage of piscivores awaiting new recruits to the nursery. This highlights the challenge confronting researchers in diverse tropical estuarine systems to uncover detailed predator-prey relationships, such as those examined in temperate estuaries (e.g. Juanes \& Conover 1995, Buckel \& Conover 1997 , Buckel et al. 1999, Juanes et al. 2001).

\section{Prey fish size and identity}

The piscivore assemblage consumed a range of prey including many small fishes. Among the common prey fish taxa found in this study, Ambassis telkara and 3 species of Leiognathus first appeared in samples from a nearby estuary at between 10 and $20 \mathrm{~mm}$ in length, followed by rapid growth within the nursery (Robertson \& Duke 1990b). Our observations indicate that most of the common prey fish taxa found in this study recruit to the nursery at around this size. Another common small fish prey, the gobiid Acentrogobius viridipunctatus is a small species occurring at sizes between 10 and $50 \mathrm{~mm}$ in shallow sandy estuarine habitats in this region ( $M$. Sheaves unpubl. data). Despite its small size, it is likely that $A$. viridipunctatus $<20 \mathrm{~mm}$ are also relatively new recruits to the nursery. It is, therefore, reasonable to conclude that the majority of fish prey $<20 \mathrm{~mm}$ consumed by predators in this study were new recruits.

All of the smaller $(<100 \mathrm{~mm})$ piscivores examined in this study preyed primarily on small new recruits (e.g. Fig. 6). Large individuals of the carangids Scomberoides lysan, Caranx ignobilis and C. sexfasciatus consumed a broad size range of fish prey, including large numbers of small new recruits. In contrast, larger individual Platycephalus fuscus and Pseudorhombus arsius did not prey on new recruits $<20 \mathrm{~mm}$. Based on the slope of the lower boundary of the predator-prey size relationship for Platycephalus arenarius, and the sparse available data for larger Sphyraena spp. and Scomberomorus semifasciatus, it is probable that larger individuals of these species would mostly consume relatively large fish prey (Fig. 6, Table 2).

While some large piscivores do consume large numbers of small fish prey as suggested by Blaber (1980), this cannot be generalised to apply to the whole piscivore assemblage of shallow water nurseries. Large individuals of several common piscivores do not appear to prey heavily on small new recruits, while small individuals of all piscivorous species are physically constrained to consume small prey. Juveniles of many members of the piscivore assemblage such as the carangids, sphyraenids and scomberids are commonly reported from estuaries in the tropical IndoWest Pacific (Blaber 1980, Blaber et al. 1985, 1989, Blaber \& Milton 1990). Consequently, new recruits to the shallow nursery are going to encounter far more small piscivorous fishes than large ones.

\section{Implications and conclusions}

The shallow water nursery habitats examined in this study contained an assemblage of piscivores that was diverse in terms of species composition, size structure, predation strategies and prey types. The diversity in the estuarine fish communities and the unpredictable timing of recruitment of either predators or prey highlight the challenge in predicting predation pressure on new recruits entering shallow estuarine nurseries in this region. It is clear, however, that the piscivore assemblage is far larger and more diverse than previously considered (e.g. Blaber 1980, Salini et al. 1990), and has potential to be a major structuring force on estuarine fish communities.

Within the piscivore assemblage, it is difficult to determine relative impacts of different piscivores on prey fish populations. Individual carangids can consume large numbers of demersal juveniles utilising the shallow nursery (e.g. Leiognathus spp., Sillago spp. and Gerres filamentosus) but also prey heavily on pelagic clupeoids (Fig. 6e-h). Mobile predators such as the carangids may only feed sporadically in shallow water habitats, in a similar manner to their transient feeding on coral reefs (Hixon \& Carr 1997). The coexistence of pelagic and demersal prey adds further complexity to the structuring of predation pressure by carangids on individual cohorts of recruits in the shallow nursery. The more sedentary piscivores such as 
platycephalids, and the small and minor piscivores, tend to consume fewer fish prey per predator but feed mainly on demersal fish prey and probably spend most of their time within the shallow nursery. The combined impacts of the mobile and sedentary piscivores in shallow tropical estuarine nurseries may be analogous to the effects of transient and resident piscivores that combine to structure coral reef fish communities (Hixon \& Carr 1997).

In addition to the range of predation strategies, the relative abundance of different members of the piscivore assemblage will contribute significantly to the overall impact of each species or size class of piscivore on prey fish populations. However, it is difficult to compare the abundances of piscivores with different susceptibilities to different gears, thus presenting a significant challenge in assessing their relative impacts on prey fish populations. Despite such challenges, it is apparent from the clearer definition of the piscivore assemblage provided by this study that there is great potential for significant mortality of fish recruiting into shallow tropical estuarine nurseries. The idea that shallow nursery habitats have low predation pressure because of a few, large, primarily piscivorous fishes is clearly too simplistic a view of nursery ground functioning. While the present study contributes nothing to our understanding of the impact of predation in shallow estuarine waters relative to alternate nursery habitats and thus to our understanding of estuarine nursery ground value, it clearly shows that predation may be a major structuring force shaping shallow water estuarine fish assemblages.

Acknowledgements. We thank J. Collins for his extensive help with photography for the otolith catalogue, and J. Wilson for her contribution of dietary data. Four anonymous reviewers provided comments that greatly improved this manuscript. This research was funded by the Cooperative Research Centre for Coastal Zone, Estuary and Waterway Management (Coastal CRC).

\section{LITERATURE CITED}

Blaber SJM (1980) Fish of the Trinity Inlet system of north Queensland with notes on the ecology of fish faunas of tropical Indo-Pacific estuaries. Aust J Mar Freshw Res 31: 137-146

Blaber SJM (1982) The ecology of Sphyraena barracuda (Osteichthyes: Perciformes) in the Kosi system with notes on the Sphyraenidae of other Natal estuaries. S Afr J Zool 17:171-176

Blaber SJM (1986) Feeding selectivity of a guild of piscivorous fish in mangrove areas of northwest Australia. Aust J Mar Freshw Res 37:329-336

Blaber SJM (2000) Tropical estuarine fishes: ecology, exploitation and conservation. Blackwell Science, Oxford

Blaber SJM, Blaber TG (1980) Factors affecting the distribution of juvenile estuarine and inshore fish. J Fish Biol 17: 143-162
Blaber SJM, Milton DA (1990) Species composition, community structure and zoogeography of fishes of mangrove estuaries in the Solomon Islands. Mar Biol 105:259-267

Blaber SJM, Young JW, Dunning MC (1985) Community structure and zoogeographic affinities of the coastal fishes of the Dampier region of north-western Australia. Aust J Mar Freshw Res 36:247-266

Blaber SJM, Brewer DT, Salini JP (1989) Species composition and biomasses of fishes in different habitats of a tropical northern Australian estuary: their occurrence in the adjoining sea and estuarine dependence. Estuar Coast Shelf Sci 29:509-531

Boesch D, Turner RE (1984) Dependence of fishery species on salt marshes: the role of food and refuge. Estuaries 7 : 460-468

Breiman L, Friedman JH, Olshen RA, Stone CG (1984) Classification and regression trees. Wadsworth International Group, Belmont, CA

Buckel JA, Conover DO (1997) Movements, feeding periods and daily ration of piscivorous young-of-the-year bluefish, Pomatomus saltatrix, in the Hudson river estuary. Fish Bull 95:665-679

Buckel JA, Conover DO, Steinberg ND, McKown KA (1999) Impact of age-0 bluefish (Pomatomus saltatrix) predation on age-0 fishes in the Hudson River estuary: evidence for density-dependent loss of juvenile striped bass (Morone saxatilis). Can J Fish Aquat Sci 56:275-287

Carr MH, Hixon MA (1995) Predation effects on early postsettlement survivorship of coral-reef fishes. Mar Ecol Prog Ser 124:31-42

Cleveland WS (1979) Robust locally weighted regression and smoothing scatterplots. J Am Stat Assoc 74:829-835

De'ath G, Fabricius KE (2000) Classification and regression trees: a powerful yet simple technique for ecological analysis. Ecology 81:3178-3192

Gould WW (1992) Quantile regression with bootstrapped standard errors. Stata Tech Bull 9:19-21

Hartman KJ, Brandt SB (1995) Trophic resource partitioning, diets, and growth of sympatric estuarine predators. Trans Am Fish Soc 124:520-537

Haywood MDE, Heales DS, Kenyon RA, Loneragan NR, Vance DJ (1998) Predation of juvenile tiger prawns in a tropical Australian estuary. Mar Ecol Prog Ser 162: 201-214

Hixon MA, Carr MH (1997) Synergistic predation, density dependence, and population regulation in marine fish. Science 277:946-949

Hyslop EJ (1980) Stomach contents analysis: a review of methods and their application. J Fish Biol 17:411-429

Jobling M, Breiby A (1986) The use and abuse of fish otoliths in studies of feeding habits of marine piscivores. Sarsia 71 : 265-274

Juanes F, Conover DO (1995) Size-structured piscivory: advection and the linkage between predator and prey recruitment in young-of-the-year bluefish. Mar Ecol Prog Ser 128:287-304

Juanes F, Buckel JA, Scharf FS (2001) Predatory behaviour and selectivity of a primary piscivore: comparison of fish and non-fish prey. Mar Ecol Prog Ser 217:157-165

Komori K (2001) Glassfishes (Ambassidae) of Australia and Papua New Guinea: a morphological and molecular approach to species identification and zoogeography. PhD thesis, Macquarie University, Sydney

Laegdsgaard P, Johnson CR (1995) Mangrove habitats as nurseries: unique assemblages of juvenile fish in subtropical mangroves in eastern Australia. Mar Ecol Prog Ser 126:67-81 
Manderson JP, Phelan BA, Bejda AJ, Stehlik LL, Stoner AW (1999) Predation by striped searobin (Prionotus evolans, Triglidae) on young-of-the-year winter flounder (Pseudopleuronectes americanus, Walbaum): examining prey size selection and prey choice using field observations and laboratory experiments. J Exp Mar Biol Ecol 242:211-231

Manderson JP, Phelan BA, Stoner AW, Hilbert J (2000) Predator-prey relations between age-1+ summer flounder (Paralichthys dentatus, Linnaeus) and age-0 winter flounder (Pseudopleuronectes americanus, Walbaum): predator diets, prey selection, and effects of sediments and macrophytes. J Exp Mar Biol Ecol 251:17-39

Martin TJ, Blaber SJM (1983) The feeding ecology of Ambassidae (Osteichthyes: Perciformes) in Natal estuaries. S Afr J Zool 18:353-362

McIvor CC, Odum WE (1988) Food, predation risk and microhabitat selection in a marsh fish assemblage. Ecology 69: 1341-1351

Patterson AW, Whitfield AK (1996) The fishes associated with an intertidal salt marsh creek in the Kariega estuary, South Africa. Trans R Soc Afr 51:359-364

Patterson AW, Whitfield AK (2000) Do shallow-water habitats function as refugia for juvenile fishes? Estuar Coast Shelf Sci 51:359-364

Robertson AI, Duke NC (1987) Mangroves as nursery sites: comparisons of the abundance and species composition of fish and crustaceans in mangroves and other nearshore habitats in tropical Australia. Mar Biol 96:193-205

Robertson AI, Duke NC (1990a) Mangrove fish-communities in tropical Queensland, Australia: spatial and temporal patterns in densities, biomass and community structure. Mar Biol 104:369-379

Robertson AI, Duke NC (1990b) Recruitment, growth and residence time of fishes in a tropical Australian mangrove system. Estuar Coast Shelf Sci 31:723-743

Rozas LP, Hackney CT (1983) The importance of oligohaline estuarine wetland habitats to fisheries resources. Wetlands 3:77-89

Ruiz GM, Hines AH, Posey MH (1993) Shallow water as a

Editorial responsibility: Otto Kinne (Editor-in-Chief), Oldendorf/Luhe, Germany refuge habitat for fish and crustaceans in non-vegetated estuaries: an example from Chesapeake Bay. Mar Ecol Prog Ser 99:1-16

Salini JP, Blaber SJM, Brewer DT (1990) Diets of piscivorous fishes in a tropical Australian estuary, with special reference to predation on penaeid prawns. Mar Biol 105:363-374

Salini JP, Brewer DT, Blaber SJM (1998) Dietary studies on the predatory fishes of the Norman River estuary, with particular reference to penaeid prawns. Estuar Coast Shelf Sci 46:837-847

Scharf FS, Buckel JA, Juanes F, O'Connor DO (1997) Estimating piscine prey size from partial remains: testing for shifts in foraging mode by juvenile bluefish. Environ Biol Fish 49:377-388

Scharf FS, Juanes F, Sutherland M (1998) Inferring ecological relationships from the edges of scatter diagrams: comparison of regression techniques. Ecology 79:448-460

Sheaves M (1995) Large lutjanid and serranid fishes in tropical estuaries: are they adults or juveniles? Mar Ecol Prog Ser 129:31-40

Sheaves M (2001) Are there really few piscivorous fishes in shallow estuarine habitats? Mar Ecol Prog Ser 222: 279-290

Shenker JM, Dean JM (1979) The utilisation of an intertidal salt marsh creek by larval and juvenile fishes: abundance, diversity and temporal variation. Estuaries 2:154-163

Sogard S M (1997) Size-selective mortality in the juvenile stage of teleost fishes: a review. Bull Mar Sci 60(3):1129-1157

Webster MS (2002) Role of predators in the early postsettlement demography of coral reef fishes. Oecologia 131:52-60

Webster MS, Almany GR (2002) Positive indirect effects in a coral reef fish community. Ecol Lett 5:549-557

Whitfield AK, Blaber SJM (1978) Food and feeding ecology of piscivorous fishes at Lake St Lucia, Zululand. J Fish Biol 13:675-691

Yanez-Arancibia A, Dominguez ALL, Pauly D (1994) Coastal lagoons as fish habitats. In: Kjerfve B (ed) Coastal lagoon processes. Elsevier, Amsterdam, p 363-376

Submitted: January 26, 2004; Accepted: December 7, 2004 Proofs received from author(s): March 31, 2005 